\title{
THE USE OF FIRST LANGUAGE IN ENGLISH AS A FOREIGN LANGUAGE CLASSROOMS
}

\author{
Itha Priyastiti \\ ipriyastiti@unkriswina.ac.id \\ Universitas Kristen Wira Wacana Sumba
}

\begin{abstract}
Discussions of the second language (L2) pedagogy have been studied not only in the language and education fields. Experts working in the psychology field also propose theories on applied linguistics because L2 acquisitions involve external and internal processes. However, despite numerous studies on the field, it appears that an issue regarding the use of first language (L1) still creates continuous debates. Although arguments opposing the use of first L1 present compelling theories as to their rationale, they appear to overlook the context in which teaching and learning process takes place. The studies were either conducted in English as a Second Language (ESL) or English as a Foreign Language (EFL), where teachers are native speakers who do not share the same L1 with students. Considering the uniqueness in classroom contexts, this paper is not going to argue or take sides on the conflicting views on the use of L1. Instead, it attempts to acknowledge the gap of the context in language teaching used in previous studies. Using a sociocultural theory, this article will describe the beneficial use of L1 with a focus on its use by teachers in an EFL context where teachers share the same L1 with students.
\end{abstract}

Keywords: first language, English as a Foreign Language, sociocultural theory

\section{INTRODUCTION}

Speaking of teaching and learning approaches, the use of first language (L1) in English classrooms has created rooms for debates in the second language acquisition discussions. It is believed that when individuals learn a new language, they follow the same process as the first language acquisition. Unfortunately, perceived from the view, it is argued that L1 carries potential errors because it may initiate language transfer (Selinker \& Lakshmanan, 1993). Departed from the argument, teachers need to minimize any possible errors during the second language learning process to maximize the mastery of the new language. Another notion opposing the use of L1 relates to students' motivation. It is argued that giving maximum exposure to TL will send a message on the language importance. Therefore, it will encourage positive ambiance, enhance learners' motivation as they see the importance of the language, and eventually, provide learners with greater opportunity to learn (Turnbull, 2001; Turnbull \& Arnett, 2002). In other words, the use of L1 is prone to major risks to learners' language development; and hence, the use of exclusive target language (TL) is perceived as more plausible.

Despite numerous writings showing strong support for the monolingual way of teaching English as the target language, there are some gaps in the context of discussion. Firstly, most articles underlined their points of support to the use of maximum TL, appear to heavily rely on second language acquisition (SLA) theories. An article by Derakhshan and Karimi (2015), which 
describes L1 interference to L2 learning process, suggests that when L1 is used, learners are prone to make errors because learners tend to transfer more than one aspect, i.e., form; meaning; and culture, from their L1 to L2. Although the article thoroughly discusses L2 acquisition process, it does not mention the context in which English language teaching (ELT) takes place. Secondly, the notion of L1 avoidance is mostly carried by teachers who do not share the same L1 with students or where the students speak different L1s. (Butzkamm, 2003) mentions that studies that oppose the use of L1 are proposed by native speakers (NS) of the TL who teach at the FL setting. They use the argument that using L1 in that context would cause complexity in language learning because if teachers and the students do not understand each other's language, there will not be any achievement in language learning. However, opposing the use of L1 appears to be an excuse of NS teachers for not being aware of the cultural background where the language learning takes place. The lacking knowledge of to target language and culture in which they are teaching may become one of the reasons for supporting the concept of the monolingual approach (Butzkamm, 2003; Hobbs et al., 2010; Polio \& Duff, 1994).

In other words, studies opposing the use of L1 appeared to argue more on the theory side rather than seeing the practical realm in classrooms where considerations on the choice of language used are determined by some factors. Furthermore, distinguishing the context where the LT is taught is necessary because each language classroom has unique characteristics. Therefore, overgeneralizing the teaching and learning context may send false messages to language practitioners; and thus, prone to disrupt the teaching and learning process.

\section{METHODS}

Considering the uniqueness in classroom contexts, this paper is not going to argue or take sides on the conflicting views on the use of L1. Instead, it attempts to acknowledge the gap of the context in language teaching used in previous studies. Therefore, this article attempts to describe the beneficial use of L1 both by students and teacher in foreign language (FL) classroom context, where some inclusions and exclusions of references are made to avoid overgeneralization. The focus of discussion will use the context as follows: 1) TL is the target language in FL classroom context, not in second language (SL);2) teacher shares the same language with the students; and 3 ) at the circumstance that students have lower to intermediate proficiency level in TL. The paper will first present theories that both opposing and supporting the use of L1 to give fair perspectives on the theoretical frameworks underpinning the prominent studies on the topic. Using the theoretical framework, the following part of the article will describe the roles of L1; and classroom discourses may be benefited from the use of L1. Finally, the paper will make a brief conclusion as well as propose some implications of the discussion for language teaching classrooms.

\section{DISCUSSION}

\section{L1 and second language acquisition theories}

Some experts believe that the contradictory views on L1 use in TL classrooms are stemmed from early language teaching approaches (Antón \& Dicamilla, 1998; Butzkamm, 2003; Cook, 2001; Cummins, 2007; Polio \& Duff, 1994). The early teaching approach, known as the direct method, believes in the similarity between learning a foreign language and acquiring the first language. 
This prominence suggests an idea that when children acquire their L1, they should not receive interventions from other language(s), unless it will prevent them to successfully be proficient in the language. Therefore, the same occurrence needs to be applied to learners of L2 and FL, in which to achieve successful TL learning, L1 should be avoided. In consequence, the direct method view suggests that teachers administer classroom interaction exclusively using TL (CelceMurcia, 2014; Hall, 2011). Sharing a similar view to the direct method, audiolingual approach holds that learning TL can be accomplished by following a certain pattern of stimulus, response, and reinforcement. Further, it is argued that to gain successful language learning, reinforcement and response are developed through drills and repetition in which errors should be minimized. Meanwhile, the stimulus is constructed via clear context and model (Hall, 2011, pp. 64-65).

Later views in language teaching that do not support the use of L1 are Krashen's input hypothesis and Long's interaction hypothesis. Input hypothesis presents $i+1$, where ' $i$ ' is the language competence already acquired and ' 1 ' is the language input beyond the competence acquired. It proposes that input is a crucial factor in attaining language, in which comprehensible and meaningful input would determine successful language acquisition. Viewed from the hypothesis, L1 is considered ' $i$ ' or less comprehensible input in language learning and in consequence, affects learners' TL acquisition. Meanwhile, the interaction hypothesis brings an idea that interaction is one critical component in learning language because communication between peers and with the teacher may stimulate language acquisition. Long suggests that collaborative work in language learning would be helpful to accomplish the goal if it is done in a complex and comprehensible way. Similar to Krashen's input hypothesis, L1 is regarded as too simple and will not benefit language learners (Hall, 2011). Another view is the contrastive analysis hypothesis $(\mathrm{CAH})$, which believes that negative transfer and errors of L1 background groups of TL learners can be anticipated through coherent comparisons of L1 and TL. It implies the notion that L1 impedes the TL learning process. Cook (2001) describes that from CAH reasoning, language compartmentalization is developed. The argument from language compartmentalization claims that L1 can influence TL acquisition in a positive or negative way. Further, Cook illustrates how language learners usually compare patterns, words, or structures with his/her L1, which might result in an incorrect outcome in TL production or understanding (p. 407). This argument implies that to avoid errors caused by L1 background, exclusive use of TL is more plausible.

On the opposite side, most studies that support the use of L1 in TL classrooms are underpinned by the sociocultural theory of social interaction model developed by (Vygotsky, 1978). It suggests that language is social means of interaction, which becomes a primary semiotic system and needs not to be avoided (Cook, 2001; Dicamilla \& Antòn, 2012). Sociocultural theory is similar to Long's interaction theory about the importance of interaction because the two notions acknowledge the role of the cognitive process during language learning. However, social constructivists share different approaches. Unlike Long's interaction theory, which emphasizes the effect of interaction on language processing within learners' brains, the sociocultural point of view highlights the interaction between teachers-learners and or learners-learners. In brief, the theory holds one contrasting view to other second language acquisition notions because sociocultural emphasizes the intertwined connection between interaction and language development. Instead of perceiving L1 as a potential source for errors, socio-culturalists seek possible alternatives of using L1 as an additional tool to assist the process of language learning; 
and thus, it is how to make use of what learners already have in them to learn (Butzkamm, 2003; Ohta, 1995).

The theory was strengthened with the concept of Zone Proximal Development (ZPD). Coined by Vygotsky, ZPD is defined as "the place where, working with peers and 'better others', learners can work at a level that would otherwise be beyond their reach" (Hall, 2011, p. 252). Similarly, (Lightbown \& Spada, 2013) describe ZPD as " ... a situation in which the learner can perform at a higher level because of the support (scaffolding) offered by an interlocutor" (p. 118). In other words, ZPD emphasizes the importance of interaction between the novice and the more proficient in language learning (Cárdenas-Hagan et al., 2007; Cook, 2001; Dicamilla \& Antòn, 2012; Hall, 2011).

\section{Roles of L1 in Language Classrooms}

Cognitive Role. The cognitive role of L1 in language classroom relates to the learners' mind processing where the interaction between teacher and student become input into the intake. Vygotsky (1978) argues that the mental functions of an individual can be developed through social interaction with the more proficient speakers then internalized into the brain. After new information being internalized, the knowledge gained from social interaction can be carried out autonomously. Another premise supports the cognitive benefit in teacher-students interaction state that through interaction with teachers whose knowledge in TL is higher, learners will be provided with cognitive support to work in higher level. Referred to sociocultural theory, the interaction between teachers and learners can be used by learners to regulate the input, which later can be useful to control the situation, organize, and plan action (Alegría de La Colina \& Del Pilar García Mayo, 2009; Antón \& Dicamilla, 1998). In other words, the interaction between teacher and learners is a critical process in constructing new knowledge. When the teachers use L1 in interacting with students, the language can be a mediating tool to achieve the purpose. (Butzkamm, 2003) states that L1 is the authentic source to endorse a faster learning process because it is already in learners' self. Therefore, the choice of language when the teacher interacts with students must promote the development of vocabulary, concept knowledge, and language. Cárdenas-Hagan et al. (2007) support the idea by stating that elements of learners' language development are correlated to the language of instruction that the teacher uses in interaction. Furthermore, there are situations in which the use of L1 by the teacher can be somewhat helpful to make sure that the learning goal is achieved more efficiently compared to when teachers use exclusive TL.

Given the situation where learners face linguistic difficulties that restrain them from understanding, teachers with belief about best practice to apply L1 in their classroom provides input in the L1 (Copland \& Neokleous, 2011). This is in line with the idea of 'principled eclecticism'. Based on their study, it was reported that after some attempts from teachers to explain, the students did not understand the language systems and skills. L1 was finally used when there is an increasing level of complexity that might be too difficult for beginner and intermediate level learners to understand. Antón and Dicamilla (1998) also found that their beginner learners got benefit from the use of L1 in interaction, in which they are provided with scaffolding help and mediating process. When conveying messages using L1, teacher assists students to process information with the language that they are able to understand. The purpose of this action is to give students opportunity to digest the instruction and undertake it cognitively. In sum, viewed from the sociocultural framework, L1 is an important tool facilitating cognitive 
benefit in which teacher can ease the difficulties of language features and make the input more comprehensible for learners (Macaro, 2001).

Affective Role. Affective refers to issues related to social and personality, like temperament, emotions, and how humans feel towards information, people, and thoughts (Levine, 2003; Ortega, 2013). As for language learning, it is argued that affective filter is closely related to the situation in which learners can either be motivated or demotivated to learn the new language because of certain aspects. Krashen (1982) states that one element influencing the ability to learn a language is the 'affective filter', in which learners are in a relaxed state of mind so that they are ready to acquire new knowledge (as cited in Hall, 2011). In his study, Levine (2003) proposes TL-use anxiety, where the amount of teacher's TL use has a positive correlation with the students' sense of anxiety. He comes with the hypothesis that more TL might cause higher anxiety for students.

Regarding the focus of this paper is classrooms in the FL context, where students have a low level of proficiency and limited exposure to TL. Levine's hypothesis seems to be reasonable. In order to achieve the objective of language learning, a relaxed atmosphere is essential to maintain learners' motivation. Less skillful learners may feel demotivated if the teacher presents them with language that they are not proficient in. During a survey for his study, Corcoran (2008) found that students perceived the use of exclusive TL by their teacher as less helpful. One student mentioned that when the teacher presented using exclusive TL, he felt insecure and anxious. Similarly in their study, (Khairunnisa \& Lukmana, 2020) found that 94\% teachers feel the use of L1 decrease learners' anxiety. Although only in forms of greetings, the classroom ambience is less intimidating. The result is expected for Indonesian context, where English is taught as a foreign language, learners have limited exposure to the language. Therefore, English is often perceived as a hard subject at school so students with lower to intermediate proficiency level feel English classroom is daunting. For that reason, using L1 as the language that are familiar to learners may help to ease their tension to the subject. Two studies suggested that the use of L1 by the teacher may become a help to lower students' 'affective filter' and their motivation in language learning. Polio and Duff (1994) also presented a statement by one of the teachers who said that L1 is useful to create a relaxed ambiance in beginner-level language classrooms. In brief, the affective benefits of using the LI can bring a positive mood; and therefore, it needs to be pinpointed that L1 plays an important role in the FL classrooms.

Concerning the importance of interaction among learners, (Dicamilla \& Antòn, 2012) state that cognitively, L1 is the medium for private speech, especially when learners find challenging tasks. Described as self-talk, private speech is a spontaneous action, especially to learners with lower proficiency of TL. When learners interact with more skilled interlocutors, the new knowledge will be internalized until it can be performed individually. By performing a private speech in their L1, learners may manage their anxiety during the learning process; and hence, they will be able to arrange, design, and synchronize activities once they gain self-control (Alegría de La Colina \& Del Pilar García Mayo, 2009; Antón \& Dicamilla, 1998; Centeno-Cortés \& Jiménez Jiménez, 2004; Cummins, 2007; Dicamilla \& Antòn, 2012; Lantolf \& Beckett, 2009). With that being said, L1 is seen as a valuable means in the learning process of TL because it serves as a cognitive tool for learners to self-control and control things around them, including language. Compared to the use of exclusive TL, L1 facilitates learners cognitively to do perform language analysis then carry the tasks to a higher level Storch \& Wigglesworth (2003). 


\section{L1 for Instruction Purposes}

Studies have shown different points where it will be beneficial for the teacher to use L1 when interacting with the students. This paper tries to sum up some areas where the principled use of L1 can be favorable for FL context and students with a low level of proficiency.

The use of $\mathbf{L 1}$ for classroom administrative vocabulary. Typically, teachers use L1 for classroom administrative vocabulary at the beginning of class meetings, within the context of a classroom for beginner learners. Polio and Duff (1994) describe the main reason teachers use L1 in classroom administrative vocabulary is to make sure that students understand what to do. Edstrom (2006) gives a similar reason when she mentions that in early meetings of class, L1 is used to explain course requirements, policies, and rules related to the course. The concern of using L1 in this context is that learners with a low level of proficiency might find difficulties in understanding the course's requirement if they are delivered in exclusive TL. In her reflection paper, she said that L1 has been helpful for her to assist students to comprehend challenging materials.

Other than learning grammatical structure, learning language is always related to know the meaning of words. Teachers usually use L1 to deliver and check the meaning of words and or sentences to make sure that the students understand the material; and thus, translating from L1 to TL or vise versa is a typical way when students are still at the early level of TL. Butzkamm (2003) argues that language learner needs to understand the message from the meaning. Therefore, providing them with translation might prevent errors in comprehending the information. Similarly, Storch and Wigglesworth (2003) propose that the L1 can be a favorable tool, especially in meaning-focused activities. They suggest that L1 allows students to talk about the language focus being discussed. The benefit of using L1 to assist learners in terms of vocabulary acquisition is also presented in a study conducted on two age groups, i.e., elementary school and university students in Korea (Lee \& Macaro, 2013). The result shows that instead of the teacher's use of exclusive TL, students prefer the interchangeable use of L1 and TL to bridge their comprehension of the words' meaning. In other words, L1 facilitates the students' learning process as it has been helpful to recall their knowledge. Commonly, the interaction between teacher and students in checking comprehension about the material also includes question and answer. The use of L1 provides learners with both cognitive and affective aspects. If the communication faces particular difficulties, inserting L1 might help reduce the distress both for teachers and students. Cognitively, when teachers provide input in the TL and complication still occurs, the 'principled eclecticism' concept can be applied, in which the teacher sought a better way to solve the problem. If teachers see that the issue will hinder the learning process, using L1 can be one alternative to resolve it (Butzkamm, 2003; Cook, 2001; Copland \& Neokleous, 2011).

The use of L1 for grammar instruction. Grammar as a language system and skills is an aspect of language pedagogy that has been a challenge for both teachers and learners. Although some argue that grammar does not necessarily be taught as a single subject; and that it can be integrated through all four skills, the case might be different where English is taught as a foreign language. Classrooms become a solely learning resource for learners; and hence, learners have limited exposure to the language when they are not at school. In consequence, language teachers have a 
significant role to assist learners in understanding grammar complexities. Under the circumstance, teachers need to make a wise decision to choose which language to explain grammar.

In addition to the context of EFL, teachers' intention to use L1 for grammar instruction is related to the proficiency level of the students. In their study, Polio and Duff (1994) interviewed teachers who used L1 in their FL classroom. They argued that L1 was used to explain grammar because students were at the beginning level of learning the TL. Therefore, using exclusive TL to teach grammar may complicate the learning process. Edstrom (2006), Cook), (2001), and Copland and Neokleous (2011) share a similar result in their studies, in which teachers decided to use recourse to L1 because of the complexity in marking particular grammatical points using TL. To sum up factors that influence teachers' decision to use L1 for grammar can be seen from a study conducted by Duff and Polio (1990). The study, which was conducted in thirteen different FL classes at the university level, found that the use of L1 by teachers in the classroom was varied from as low as ten percent to considerably as high as one hundred percent. The study set two variables influencing teachers' decisions in using L1. First is the 'classroom external' factors, which include learners' proficiency in TL and departmental policy related to the role of TL. The second variable is a 'classroom internal' factor, which is related to difficulty in materials. The study reports that teachers in the FL context felt the necessity to use L1 because they were afraid if the use of exclusive TL would hamper the learners from getting important information, especially for challenging points, like grammar.

\section{L1 for Classroom Management}

The use of L1 for empathy/solidarity. Learning English as a foreign language may be frustrating for learners. Therefore, it is important to maintain a classroom atmosphere by knowing student's feelings, beliefs, and attitudes (Butzkamm, 2003; Littlewood \& Yu, 2011; Polio \& Duff, 1994). Using the term 'naturalness', Cook (2001) explains the benefit of using L1 where teachers treat students 'as their real selves rather than dealing with assumed L2 personas' (p. 416). In this situation, L1 can be a helpful medium to show empathy and a sense of solidarity. Similarly, in their study to university FL classrooms, Polio and Duff (1994) mention that compared to TL, L1 was more useful for interpersonal, rapport-building purposes. Further, it is said that teachers prefer to use L1 to show their concern and make jokes in order to diminish stressful situations in the classroom. Presenting students with humor in students' language is believed to be efficient to relieve tension in the classroom, especially when the material is complex and challenging.

In the context of EFL, where teachers come from the same place and speak the same language as learners, they also share the same cultural context. Having teachers and learners in the same local culture and context makes them embrace similar values; and thus, the use of L1 is celebrated for building rapport. A study conducted in EFL secondary schools in Turkey, Sali (2014) suggests that sharing the same language and socio-cultural identity allows teachers to make an affective connection with students. She found that teachers frequently use Turkish to praise the students' work and achievement because L1 gave a sense of informal and more personal so it gave a more intimate sense. Similar result was found in studies to English teachers in Indonesia, where teachers use L1 to build relationship (Khairunnisa \& Lukmana, 2020; Saputra, 2017).

The use of L1 to maintain discipline and give feedback. Dealing with students, misbehaviors that lead to negative ambiance may occur during the teaching and learning process; and thus, it is 
common that teachers make some attempts to maintain discipline. In the context where teachers share the same language with students, Cook (2001) argues that in order to keep control over the classroom, L1 is frequently used because of its efficiency. He states, "saying 'Shut up or you will get a detention' in the LI is a serious threat rather than the practice of imperative and conditional constructions" (p. 15). Similarly, in her study to EFL schools in Turkey, Sali (2014) mentions that one of the main reasons teachers use L1 is to regulate classroom interactions and proceedings efficiently because L1 helps teachers deliver their message in a more powerful manner. Affectively, students' limited vocabulary and exposure to TL, the use of L1 can have a direct impact on students' behavior given the fact that they understand better the tone and cultural values in the language.

Besides maintaining discipline, there are situations when teachers need to give feedback for what students have accomplished. Telling students how well they have achieved using their language will sound more real (Macaro, 1997 as cited in Cook, 2001, p. 416)). It is frequent that learners find it easier to receive feedback in L1 so they know parts that need improvement. It is in line with the finding in a study conducted by Hasrina et al. (2018) on high school students in Indonesia. The students mentioned that when the teacher delivered the feedback in L1, they could see the reason why some points were considered wrong. A similar motivation was found from the teachers' perception, where they felt that L1 was more effective to make corrections (Khairunnisa \& Lukmana, 2020).

\section{CONCLUSIONS AND SUGGESTIONS}

Second language acquisition theories indeed have provided an important base for discussions on language pedagogy. However, the sociocultural theory emphasizes that social interaction and language development are intertwined; and thus, it is how to make use of what learners already have in them to learn. As Butzkamm (2003) mentions that what has been possessed by learners through their L1 is not to be erased nor avoided. Therefore, despite seeing the L1 as the culprit that hinders learners from becoming successful language learners, this paper wishes to describe what could teachers do to use the L1 as an additional tool to assist the learning process.

The paper has outlined the beneficial use of L1 by teachers in interacting with students. Synthesizing several studies related to the topic, it shows that L1 can be a useful medium to teach TL under some circumstances; (a) in the context where English, as the TL, is taught in a foreign setting; (b) teacher shares the same L1 with the students; (c) students have limited exposure to the TL; (d) students' level of proficiency in TL is lower intermediate. Believing in best practice with 'principled eclecticism', there are situations when teachers see the necessity to use L1 to interact with students. However, it cannot be justified that teachers can use L1 if they do not understand the context of their classroom. From the discussion, L1 has cognitive and affective benefits and is frequently used in classroom interaction, in which teachers and students may have difficulties in vocabulary and meaning, lack of comprehension, and some features in grammar points. In the context of classroom management, teachers usually use L1 for showing empathy and solidarity or building relationships with students and to maintain discipline over the classroom.

\section{Implications of Using $\mathrm{L1}$ in FL Classrooms}

Regarding the debates on the advantages and disadvantages of using L1 in the language classroom, there cannot be a generalization of both. As Edstrom (2006) concludes, "the 
appropriate quantity of LI use by teachers cannot be defined universally..." (p. 289). It is because every language classroom has unique features in terms of social and cultural context, learners' characteristics (learning strategy, level of proficiency), institutional and or government policies (i.e., curriculum and study objectives). Therefore, it cannot be justified that using L1 or exclusive TL is the best approach. Since language is a medium of communication, both languages can be involved by creating links between them.

'Principled eclecticism' should be one milestone to help teachers become more aware of their learners' needs without overlooking the regulations in the context where they are teaching. Needs assessment and student's perception can also be useful to determine applicable yet appropriate approaches in language teaching. In brief, teachers need to study the contexts where the teaching and learning process is taking place and meet the needs of the learners with guidance from local values.

\section{Further Research}

Further research may investigate the use of L1 to more specific contexts, such as using certain countries or groups of learners rather than general categorization based on the second or foreign groups. By applying targeted settings, the supporting arguments will be stronger and plausible.

\section{REFERENCES}

Alegría de La Colina, A., \& Del Pilar García Mayo, M. (2009). Oral interaction in task-based EFL learning: The use of the L1 as a cognitive tool. IRAL - International Review of Applied Linguistics in Language Teaching, 47(3-4), 325-345. https://doi.org/10.1515/iral.2009.014

Antón, M., \& Dicamilla, F. J. (1998). Socio-cognitive Functions of L1 Collaborative Interaction in the L1 Classroom. The Canadian Modern Language Review/ La Revue Canadienne Des Langues Vivantes, 54(3), 314-342.

Butzkamm, W. (2003). We only learn language once. The role of the mother tongue in fl classrooms: Death of a dogma. Language Learning Journal, 28(1), 29-39. https://doi.org/10.1080/09571730385200181

Cárdenas-Hagan, E., Carlson, C. D., \& Pollard-Durodola, S. D. (2007). The Cross-Linguistic Transfer of Early Literacy Skills: The Role of Initial L1 and L2 Skills and Language of Instruction. Language, Speech, and Hearing Services in Schools, 38(3), 249-260. https://doi.org/10.1044/0161-1461(2007/026)

Celce-Murcia, M. (2014). Teaching English as a second or foreign language. In M. Celce-Murcia, D. Brinton, \& M. A. Snow (Eds.), Teaching English as a Second or Foreign Language (4th ed.). National Geographic Learning.

Centeno-Cortés, B., \& Jiménez Jiménez, A. F. (2004). Problem-solving tasks in a foreign language: The importance of the L1 in private verbal thinking. International Journal of Applied Linguistics (United Kingdom), 14(1), 7-35. https://doi.org/10.1111/j.14734192.2004.00052.x

Cook, V. (2001). Using the First Language in the Classroom. The Canadian Modern Language Review/ La Revue Canadienne Des Langues Vivantes, 57(3), 402-423.

Copland, F., \& Neokleous, G. (2011). L1 to teach L2: Complexities and contradictions. ELT Journal, 65(3), 270-280. https://doi.org/10.1093/elt/ccq047

Corcoran, J. N. (2008). L1 in the L2 Classroom: Framing Brazilian Teacher Beliefs and Practices. Ontario Institute for Studies in Education of the University of Toronto. 
Cummins, J. (2007). Rethinking monolingual instructional strategies in multilingual classrooms. Canadian Journal of Applied Linguistics / Revue Canadienne de Linguistique Appliquee, 10(2), 221-240.

Derakhshan, A., \& Karimi, E. (2015). The Interference of First Language and Second Language Acquisition. Theory and Practice in Language Studies, 5(10), 2112. https://doi.org/10.17507/tpls.0510.19

Dicamilla, F. J., \& Antòn, M. (2012). Functions of L1 in the collaborative interaction of beginning and advanced second language learners. International Journal of Applied Linguistics, 22(2), 160-188.

Duff, P. A., \& Polio, C. G. (1990). How Much Foreign Language Is There in the Foreign Language Classroom? The Modern Language Journal, 74(ii), 154-166.

Edstrom, A. (2006). L1 Use in the L2 Classroom: One Teacher's Self-Evaluation. The Canadian Modern Language Review, 63(2), 275-292.

Hall, G. (2011). Exploring English Language Teaching. In Exploring English Language Teaching. Routledge. https://www.taylorfrancis.com/books/9781351757928

Hasrina, N., Aziz, Z. A., \& Fitriani, S. S. (2018). First Language (L1) Use in the EFL Classroom: Perceptions of Students and Teachers. English Education Journal (EEJ), 9(3), 406-421.

Hobbs, V., Matsuo, A., \& Payne, M. (2010). Code-switching in Japanese language classrooms: An exploratory investigation of native vs. non-native speaker teacher practice. Linguistics and Education, 21, 44-59. https://doi.org/10.1016/j.linged.2009.12.004

Khairunnisa, \& Lukmana, I. (2020). Teachers' Attitudes towards Translanguaging in Indonesian EFL Classrooms. Jurnal Penelitian Pendidikan, 20(2), 254-266.

Lantolf, J. P., \& Beckett, T. G. (2009). Sociocultural theory and second language acquisition. Language Teaching, 42(4), 459-475. https://doi.org/10.1017/S0261444809990048

Lee, J. H., \& Macaro, E. (2013). Investigating age in the use of L1 or english-only instruction: Vocabulary acquisition by Korean EFL learners. Modern Language Journal, 97(4), 887901. https://doi.org/10.1111/j.1540-4781.2013.12044.x

Levine, G. S. (2003). Student and Instructor Beliefs and Attitudes about Target Language Use, First Language Use, and Anxiety: Report of a Questionnaire Study. The Modern Language Journal, 87(3), 343-364. https://doi.org/10.1111/1540-4781.00194

Lightbown, P. M., \& Spada, N. (2013). How Languages are Learned (4th ed.). Oxford University Press.

Littlewood, W., \& Yu, B. (2011). First language and target language in the foreign language classroom. Language Teaching, 44(1), 64-77. https://doi.org/10.1017/S0261444809990310

Macaro, E. (2001). Analysing Student Teachers ' Codeswitching in Foreign Language Classrooms : Theories and Decision Making. The Modern Language Journal, 85(iv), 531548.

Ohta, A. S. (1995). Applying Sociocultural Theory to an Analysis of Learner Discourse: LearnerLearner Collaborative Interaction in the Zone of Proximal Development. Issues in Applied Linguistics, 6(2), 93-121.

Ortega, L. (2013). Understanding Second Language Acquisition. Routledge.

Polio, C. G., \& Duff, P. A. (1994). Teachers' Language Use in University Foreign Language Classrooms: A Qualitative Analysis of English and Target Language Alternation. The Modern Language Journal, 3(Oct), 313-326.

Sali, P. (2014). An analysis of the teachers' use of L1 in Turkish EFL classrooms. 42, 308-318. 
Saputra, E. R. (2017). Seeing The Use of First Language Through the Eyes of Teacher and Students. Journal of Teaching \& Learning English in Multicultural Contexts, 1(2), 23-35.

Selinker, L., \& Lakshmanan, U. (1993). Language Transfer And Fossilization: The "Multiple Effects Principle.” In S. Gass \& L. Selinker (Eds.), Language Transfer in Language Learning (Revised, pp. 197-216). John Benjamins B.V.

Storch, N., \& Wigglesworth, G. (2003). Is There a Role for the Use of the L1 in an L2 Setting? TESOL Quarterly, 37(4), 760-770. https://doi.org/10.2307/3588224

Turnbull, M. (2001). There is a Role for the L1 in Second and Foreign Language Teaching, But ... The Canadian Modern Language Review/ La Revue Canadienne Des Langues Vivantes, 57(4), 531-540.

Turnbull, M., \& Arnett, K. (2002). TEACHERS' USES OF THE TARGET AND FIRST LANGUAGES IN SECOND AND FOREIGN LANGUAGE CLASSROOMS.pdf. Anпиal Review of Applied Linguistics, 22, 204-218.

Vygotsky, L. (1978). Mind in Society: The Development of Higher Psychological Processes. Harvard University Press. 